\title{
Impact of trauma and a shift in focus on healthcare
}

\section{By Jamie Seto}

Jamie is nearing completion of his Certificate in Forensic Health Sciences at British Columbia Institute of Technology (BCIT). He has experience in many areas of nursing and has been adding to his knowledge and skills by bringing principles of forensic nursing practice into his own practice. He spent a clinical practicum with Lori Baker, RN, CNCC(C), CCNC(C), Trauma Coordinator, Coastal Health, Lion's Gate Hospital, North Vancouver, BC.

His article reflects on the after effects of trauma caused by any number of reasons, as patients and families work to a new norm after a life-altering experience. Healthcare providers especially can be affected personally by the trauma of others, as well. Forensic nursing practice takes into account that it is not only the medical needs of a patient, but the inclusion of possible forensic needs, as well, that may assist patients and their families to better outcomes post trauma and violence.

\section{- Introduction by Sheila Early}

$\mathrm{T}$ rauma can be defined as: 1) an injury (as a wound) to living tissue caused by an extrinsic agent, or 2) a disordered psychological or behaviour state resulting from severe mental or emotional stress or physical injury (MerriamWebster, 2016). It can also be further broadened when you take into account that trauma does not only affect the victim. The spectrum of trauma is spread across a multitude of characteristics and people involved. According to Courtois (1993), vicarious traumatization (VT) is a transformation in the self of a trauma worker (i.e., a nurse) or helper (family member) that results from empathic engagement with traumatized clients and their reports of traumatic experiences. It is a special counter transference stimulated by exposure to the client's traumatic material (Courtois, 1993). Secondary traumatic stress is the emotional duress that results when an individual hears about the firsthand trauma experiences of another. Its symptoms can mimic those of post-traumatic stress disorder (PTSD).

Trauma and stress can be physical, emotional, financial, and/ or psychological. It can be singular in its burden, or compound itself with any combination of the aforementioned, becoming ever more cyclical and insidious in its nature from the acute through to the chronic.

According to the World Health Organization (WHO), injury kills more people each year than HIV, TB, and malaria combined, and this occurs predominantly in low-middle-income countries (WHO, 2016). Timely emergency care saves lives: if fatality rates from severe injury were the same in low- and middle-income countries as in high-income countries, nearly 2 million lives could be saved every year (WHO, 2016). This has necessitated the creation of assessment tools to streamline essential emergent care, such as the WHO Trauma Care Checklist:

http://www.who.int/emergencycare/publications/trauma-care-checklist.pdf?ua $=1$

The WHO Trauma Care Checklist was launched on August 18, 2016, at the World Trauma Congress in New Delhi, India, in collaboration with the Government of India and the WHO Global Alliance for Care of the Injured.

This is congruent with the emergent care assessment of trauma victims by trained personnel. The Trauma Nursing Core Course teaches that the first few minutes of trauma care are critical to achieve better patient outcomes. The A-I mnemonic and the Trauma Nursing Assessment will assist nurses in providing appropriate and early intervention:

A - airway with simultaneous c-spine stabilization

$\mathrm{B}$ - breathing

C - circulation

$\mathrm{D}$ - disability (neurological status)

$\mathrm{E}$ - expose patient/environmental control

$\mathrm{F}$ - full set VS/five interventions/facilitate family

$\mathrm{G}$ - give comfort

$\mathrm{H}$ - history/head-to-toe assessment

I - inspect posterior surfaces" (TNCC, 2016).

In addition to the A-I of trauma assessment, emergency departments utilize algorithms to further care of the victim. An example is Code 99 Trauma Activation. This applies to new patients and transfers. According to (Baker, 2014) activating Code 99 if the patient meets ANY of the following criteria (Table 1).

Care of the patient, whether it be a trauma in the emergency department, or a code blue on any unit, includes many members of the interdisciplinary team: physician(s), nurses, respiratory therapist(s), social worker, and pharmacist. In addition to the aforementioned roles, other personnel and services are essential in the care and management of the patient. This may, and likely includes unit clerk, laboratory technician, blood bank, ECG technician, $\mathrm{x}$-ray technologist, and hospital security. Other hospital departments are often mobilized in preparation for potential use-CT scan and operating room.

The impact of trauma is multifactoral: physical, emotional, and financial, and likely compound one another, as it is seldom a single factor alone.

Violence, as it pertains to trauma, as defined by the WHO (2017) is "the intentional use of physical force or power, threatened or 


\begin{tabular}{|c|c|c|}
\hline & Adult Criteria (16 Years of Age and Over) & $\begin{array}{l}\text { Pediatric Criteria (Less Than } 16 \\
\text { Years of Age) }\end{array}$ \\
\hline $\begin{array}{l}\text { Mechanism of } \\
\text { Injury }\end{array}$ & $\begin{array}{l}\text { Significant Mechanism of Injury } \\
\text { Adult patient trauma activation is not based on mechanism alone. } \\
\text { One of the criteria below must also be met. }\end{array}$ & $\begin{array}{l}\text { MVC_-patient thrown from vehicle } \\
\text { - prolonged extrication of }>20 \text { minutes } \\
\text { - other occupant killed/injured } \\
\text { severely } \\
\text { Pedestrian vs. Motor Vehicle-Thrown } \\
\text { Bicycle vs. Motor Vehicle-Thrown } \\
\text { Any fall from } 3 \text { times the child's height } \\
\text { or more } \\
\text { Even if none of the below criteria are } \\
\text { met, Code } 99 \text { should be activated in the } \\
\text { pediatric patient based on mechanism } \\
\text { alone. }\end{array}$ \\
\hline Physiologic & $\begin{array}{l}\text { Respiratory rate }<10 \text { or }>29 / \mathrm{min} \\
\text { Systolic blood pressure }<90 \mathrm{mmHg} \\
\text { Glasgow Coma Scale } \leq 13 \\
\text { Any patient requiring ventilatory support (i.e. BVM, Intubated) } \\
\text { Any patient requiring blood products to resuscitate in sending } \\
\text { facility (Transfers only) }\end{array}$ & \\
\hline Anatomic & $\begin{array}{l}\text { Penetrating injury to the head, neck, chest, abdomen, groin, } \\
\text { proximal extremities } \\
\text { Flail chest } \\
\text { Burns }>20 \% \text { TBSA } \\
\text { Unstable pelvic fracture } \\
\text { Amputation proximal to wrist and ankle } \\
\text { Traumatic limb paralysis (spinal injury with deficits) } \\
\geq 2 \text { proximal long-bone fractures }\end{array}$ & \\
\hline Other & $\begin{array}{l}\text { If any of these are the only criteria met, activation is optional based } \\
\text { on the EP/CRN decision: } \\
\text { Pregnant patient with significant MOI } \\
\text { Extremes of age } \\
\text { Other significant comorbidities (Cardiac disease, respiratory disease) } \\
\text { At the discretion of the EP, is considered high-risk for life or limb- } \\
\text { threatening injury }\end{array}$ & \\
\hline
\end{tabular}

actual, against oneself, another person, or against a group or community, which either results in or has a high likelihood of resulting in injury, death, psychological harm, maldevelopment, or deprivation." Whether experienced firsthand or indirectly, violence affects the lives of millions, with long-lasting consequences. The WHO compiled data from 133 countries, covering 6.1 billion people and representing $88 \%$ of the world's population. Detailed in the Global Status Report on Violence Prevention 2014:

"There were an estimated 475,000 deaths in 2012 as a result of homicide. Sixty percent of these were males aged 15-44 years, making homicide the third leading cause of death for males in this age group. Within low-and middle-income countries, the highest estimated rates of homicide occur in the Region of the Americas, with 28.5 homicides per 100,000 population, followed by the African Region with a rate of 10.9 homicides per 100,000 population. The estimated rate of homicide is in the low-and middle-income countries of the Western Pacific Region, with 2.1 per 100,000 population. Over the period from 2000 to 2012, homicide rates are estimated to have declined by just over $16 \%$ globally (from 8.0 to 6.7 per 100,000 population), and, in high-income countries, by 39\% (from 6.2 to 3.8 per 100,000 population). By contrast, homicide rates in low- and middle-income countries have shown less decline over the same period. For both upper and lower middle-income countries the decline was 13\%, and for low-income countries it was $10 \%$. Nevertheless, deaths are only a fraction of the health and social burden arising from violence."

As recognized by WHO (2016), crisis events involving exposure to trauma and sudden loss occur in all communities of the world. Orientation in psychological first aid gives responders a framework and tools to better approach and respond to victims in a natural, supportive, and practical manner. They also acknowledge that a common mistake in current humanitarian responses in many countries is to only make psychological first aid available in the absence of other care (WHO, 2016). Psychological first aid is feasible and appropriate during crises and should be complemented with other essential mental health, physical, and psychosocial activities (WHO, 2016). In the long run, all communities need to have mental health, social and educational services that address the long-term increase in needs, alongside the acute response (WHO, 2016). This needs to be multisectorial! 
This need for a multisector approach to healthcare has long been established but, unfortunately, is not widespread. In the 1990s Lynch and McCracken, both nurses (psychiatric and emergency respectively) with many years of experience and forensic expertise, recognized the necessity for a shift in paradigm. Lynch, in Forensic Nursing (2006), explains that clinical forensic practice derives from the broader field of forensic medicine and is defined as "the application of clinical and scientific knowledge to questions of the law and the civil or criminal investigation of survivors of traumatic injury and/or patient treatment involving court-related issues ( $p$. 4)" Lynch adds that living forensic patients are the survivors of criminal or liability-related injuries that result in an investigation by a legal entity. Lynch further states that "no longer can healthcare providers work in isolation from the legal issues previous delegated to law enforcement." It is the responsibility of the healthcare professionals to maintain a high index of suspicion and to protect victims. As stated in Forensic Nursing Science (Duval \& Lynch, 2010), “The application of forensic aspects of healthcare combined with the bio/psycho/social/spiritual education of the registered nurse in the scientific investigation and treatment of trauma and/or death of victims and perpetrators of violence, criminal activity and traumatic accidents. It provides direct services to individual clients and consultation services to nursing, medical- and law-related agencies, and it provides expert court testimony in areas dealing with questioned death investigative processes, adequacy of services delivery and specialized diagnoses of specific conditions, as related to nursing." This is further corroborated in Forensic Nursing (2006), McCracken's mnemonic, the ABCs of clinical forensic nursing, to assist nurses with their medico-legal responsibilities:

"A: Assessment of the victim

B: Bridge the gap; liaison with outside agencies such as law enforcement and the medical examiner

C: Chain of custody; know the methods of evidence collection and establish continuity of evidence possession and disposition

D: Documentation of findings

E: Evidence

F: Families; keep them informed

G: Going to court; be prepared to provide written or oral testimony

$\mathrm{H}$ : Hospital policies; know where and how to access your institution's forensic protocols

I: Index of suspicion; be aware of signs of abuse and violence (p. 4).”
It has long been known that trauma care providers are very good at finding out what is injured. Emergency department nurses and trauma physicians excel in the "E" part of the mnemonic of trauma care. We "expose" the patient to see what is hurt. Unfortunately, we are also very skilled at throwing away the soiled clothing, washing the wounds, applying ointments, and making judgements when we are not expertly trained in that field. There were no guidelines and, at present, I would dare to say many emergency departments lack guidelines, nor is training provided regarding basic forensic evidence collection. This statement can be corroborated by my colleagues at the Royal Columbian, Surrey Memorial and Vancouver General Hospital emergency departments. I have been told by colleagues that the first thing on their mind when stabilizing a victim of a gunshot wound, is medical care, first and foremost. It is not the intended purpose to destroy evidence and unintentionally obstruct justice, but a result of not knowing any better because of a lack of training and education. The practice of evidence preservation is not engrained in them. So, what happens as a result? In many instances, they cut through the hole created by the projectile, destroying evidence. How many individuals know that powders, particulates, and residue are deposited on the clothing and can aid in the investigation in determining the distance from the muzzle of the firearm? The only ones with definitive training and knowledge pertaining to medical care in congruence with evidence preservation are the certified Sexual Assault Nurse Examiners, and they are few and far between!

Virginia Lynch discovered this incongruence in our medical-legal system in 1982 when she had an opportunity to visit a crime laboratory. During the visit, she realized that she and her colleagues had been inadvertently destroying important evidence when crime victims came into their emergency department and, as a result, created a new nursing specialty (Elsevier, 2014). This passion has drawn many others to the cause (Sheila Early, Aimee Falkenberg, Lori Baker-several of my own esteemed instructors whom I have had the privilege of knowing), to bring to light what many would consider a special calling. A shift in perspective to want to know, to educate others about what is not taught in nursing or medical schools-forensic medicine.

\section{REFERENCES}

Baker, L. (2014). Code 99 Trauma Activation Criteria. Vancouver Coastal Health.

Courtois, C.A. (1993). Vicarious Traumatization. (As cited in Wikipedia, The Free Encyclopedia, 2016.) Retrieved from https://en.wikipedia. org/w/index.php?title=Vicarious_traumatization\&oldid=739964155

Duval, J B., \& Lynch, V.A. (2010). Forensic Nursing Science (2nd ed.). Elsevier.

Elsevier (2014). Virginia Lynch: Pioneer in Forensic Nursing. Retrieved from http://www.confidenceconnected.com/blog/2014/05/02/ virginia-lynch-pioneer-in-forensic-nursing/

Pyrek, K.M. (2006). Forensic Nursing, pp.4-5. Retrieved from https:// books.google.ca/books?id=-eDKBQAAQBAJ\&printsec $=$ frontco ver\# $\mathrm{v}=$ onepage $\& \mathrm{q} \& \mathrm{f}=$ false
Trauma Nursing Core Course (TNCC). (2016). Provider Manual (6th Ed.). Retrieved from https://notendur.hi.is/thorsj/gogn/ TNCC.pdf

Trauma. (n.d.). Retrieved from https://www.merriam-webster.com/ dictionary/trauma

World Health Organization (2014). Global Status Report on Violence Prevention 2014, VII. Retrieved from http://www.who.int/ violence_injury_prevention/violence/status_report/2014/en/

World Health Organization (2016). Trauma Care Checklist. Retrieved from http://www.who.int/emergencycare/publications/traumacare-checklist.pdf?ua $=1$

World Health Organization (2017). Violence. Retrieved from http:// www.who.int/topics/violence/en/ 